\title{
A lens into the past:The history of cataract surgery
}

\author{
Sunil Ruparelia, $\mathrm{BSc}^{1}$
}

I. Faculty of Medicine, Dalhousie University

\begin{abstract}
Cataract surgery may be one of medicine's greatest achievements, providing treatment for an otherwise blinding condition. These surgeries are among the most common operative procedures performed worldwide and are also among the most successful. The advancements that have been made in cataract management exemplify the progress that has been made in the field of surgery as a whole. Moreover, the story of the evolution of cataract surgery is fascinating. From humble origins with cataract couching to the use of ultrasonic energy in phacoemulsification, each milestone in the advancement of cataract surgery has had innovative physicians at its forefront, striving for better patient visual outcomes. This article seeks to review these major milestones, including couching, extracapsular cataract extraction, intracapsular cataract extraction, and intraocular lens implantation. Procedural steps of modern-day phacoemulsification and recent advancements that may be incorporated into future practice are also reviewed.
\end{abstract}

\section{Introduction}

$\mathrm{C}$ ataract surgeries represent one of the most common surgical operations performed in Canada and worldwide. It is estimated that globally, over 10 million cataract surgeries are performed each year ${ }^{1}$. This number appears to be increasing, as the number of cataract surgeries performed in Ontario more than doubled between 1992 and $2004^{2}$. Needless to say, it is probable that many of us have had or will have exposure to cataract surgery at some point or another. Should one's first exposure to this procedure be as a patient, it is possible that the history of the technique holds little interest. For some, the complexities of eye-surgery in its entirety would be preferred to be left a mystery. However, the current technique exemplifies the tremendous advancements that have been made in surgery, and the story of the evolution of this technique is fascinating. Even within the past 50 years, the procedure has transformed dramatically and improves visual outcomes of millions. Medical therapy has little to no value in the management of cataracts, leaving surgery as the only option to reverse cataract-induced vision loss. Modern day cataract surgeries are relatively safe procedures with success rates of $90-95 \%{ }^{3}$. Thus, at the very least, this story of advancements in cataract surgical management does generally have a happy ending. Let us take a step back and review the steps taken to develop such a procedure.

\section{Anatomy of the eye and lens}

To appreciate the history of cataract surgery, a review of basic ocular anatomy is required. The primary func- tion of the eye is to convert light into nerve impulses, which requires light to be focused on the retina. To do this, the eye uses two refractive structures. Light first enters the eye through the cornea, which forms an anterior "window" into the eye and is responsible for $2 / 3$ of the eye's refractive power. The lens is responsible for the remaining $1 / 3$ of refraction. Cataracts involve the opacification of the lens with resultant decrease in visual acuity.

As shown in Figure 1, the lens is suspended in the eye by fibers called zonules. The lens itself consists of three distinct layers. The innermost layer is called the nucleus. Nuclear cataracts are the most common and result from opacification of the nucleus ${ }^{4}$. The middle layer of the lens constitutes the lens cortex. Patients with diabetes are at increased risk of developing cortical cataracts ${ }^{5}$. A third type of cataract is the subcapsular cataract, which effects the portion of the lens just interior to the capsule, the outermost layer of the lens. As we will later see, modern day cataracts involve the removal of the nucleus and cortex, while the capsule remains behind to house the new synthetic lens implant. However, there were several techniques utilized prior to the modern procedure.

\section{Couching}

As one may expect, the origins of cataract surgery are far from the slick procedure utilized in today's practice. After all, phacoemulsification handpieces did not exist in $600 \mathrm{BC}$, when the medical record of cataract surgery begins ${ }^{6}$. Rather, surgeons initially relied on a technique called couching, which originated in India. In this technique, a needle or other sharp object is used to dislodge the lens, such that the cataract no longer 


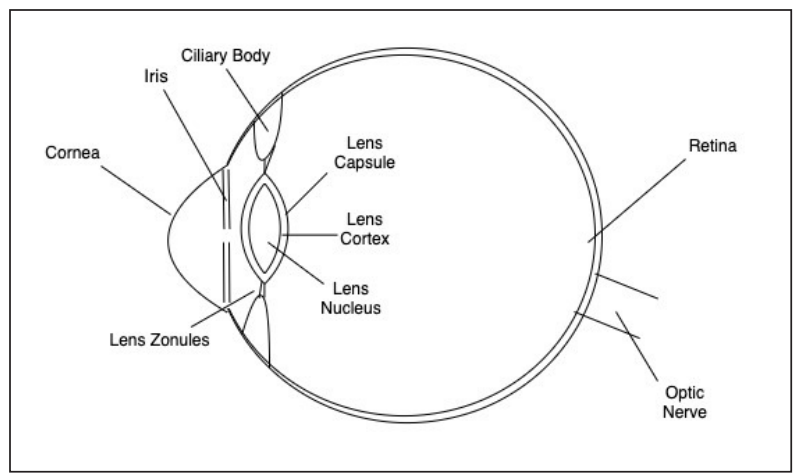

Figure I. Schematic of the eye.

obstructs the pathway of light into the eye (Figure 2). The dislodged cataract then remains in the vitreous cavity. While this procedure has obvious shortcomings, it provided a treatment for an otherwise imminent cause of blindness. Individuals would be able to see the faces of their families again, albeit from a short distance. As one would expect, the technique was associated with a myriad of complications, including infections that would result in blindness shortly after the procedure in a percentage of patients ${ }^{7}$. Due to a lack of access to modern surgical techniques, couching is unfortunately still used in some developing Nations ${ }^{8}$.

\section{Extracapsular Cataract Extraction}

There is some evidence that extracapsular cataract extraction (ECCE) began as early as $600 \mathrm{BC}$ by an Indian physician named Shashruta9. However, it is more widely accepted that the first ECCE was done in Paris by the French surgeon Jacques Daviel in $1747^{10}$. As the name suggests, extracapsular cataract extractions involve removal of the cataract while sparing the lens capsule. This technique was a significant advancement from couching, and at the time of Jacques Daviel had a success rate of approximately $50 \%{ }^{11}$. However, this technique was still far from ideal. Daviel's procedure involved a massive corneal incision (greater than $10 \mathrm{~mm}$ ). For reference, modern-day cataract surgeries involve 1-3 mm incisions. Daviel would then puncture the lens capsule and extract the lens by curettage ${ }^{12}$. Further advancements were made to this technique by German physician Albrecht von Graefe, who carried out the procedure using a much smaller scleral incision. Looking retrospectively, one can't help but admire the steady hands that these medical pioneers must have needed in order to perform such surgeries with the equipment of their time. After all, modern cataract surgeries are done under microscopy to maximise precision and safety. The extracapsular technique was replaced briefly by intracapsular cataract extraction (ICCE) for some time in the 19th century before re-emerging in the
$1970 \mathrm{~s}^{13}$. Intracapsular extractions, which involved the removal of the whole lens - M\&M shell and all - had only temporary popularity. The standard of care quickly reverted back to ECCE with the emerging concept of intraocular lens replacement.

\section{Intraocular Lens Replacement}

Sir Nicholas Harold Lloyd Ridley, an English ophthalmologist, takes much of the credit for the origins of intraocular lens (IOL) replacement. But how did Ridley see what so many others had missed? Some of the credit must be given to a medical student, Stephen Perry, who asked Ridley if he "intended to replace the extracted part of the eye" ${ }^{14}$. Later in his career during the second world war, Ridley was tasked with treating many British Royal Air Force pilots who had sustained ocular injuries ${ }^{15}$. These injuries were predominantly shards of glass embedded in the eyes of pilots after bullets shattered the canopies of their planes. Ridley noted that the glass, made of polymethyl methacrylate (PMMA), was inert in the eye. Thus, the same materials would be used by Ridley to insert the first intraocular lens in $1949^{15}$.

Eureka! We now have our first successful IOL replacement. Well, not quite. Although inert, the major pitfall of PMMA lenses was that they were rigid, and therefore required large corneal incisions in order to implant. In today's practice, most IOL replacements are foldable acrylic or silicone lenses, which allow them to be delivered through a small corneal incision. An option in current IOL implants is the use of multifocal lenses, which emerged in the 1990s to 2000s and allow for the correction of both presbyopia and ametropia. Toric intraocular lenses are commonly inserted today for correction of astigmatic refractive errors ${ }^{16}$.

\section{Modern Phacoemulsification}

Modern-day phacoemulsification is an efficient procedure done under microscopy. Phacoemulsification procedures utilize ultrasonic energy in combination with mechanical force to break up cataracts and permit aspiration. This technique was introduced in 1967 by Charles Kelman, an American Ophthalmologist ${ }^{17}$. The technique continues to be the standard of care for cataract management. In modern procedures, after anaesthetic is applied and the eye is sterilized, the physician makes a small incision (paracentesis) and main corneal incision. A viscous substance called viscoelastic, so named for its high viscosity and elastic properties, is delivered into the eye. The capsule of the lens in removed via continuous curvilinear capsulorrhexis, and hydrodissection is used to detach the lens from the surrounding cortex. The cataract is broken up mechanically and with ultrasound, and irrigation and aspiration 
A.

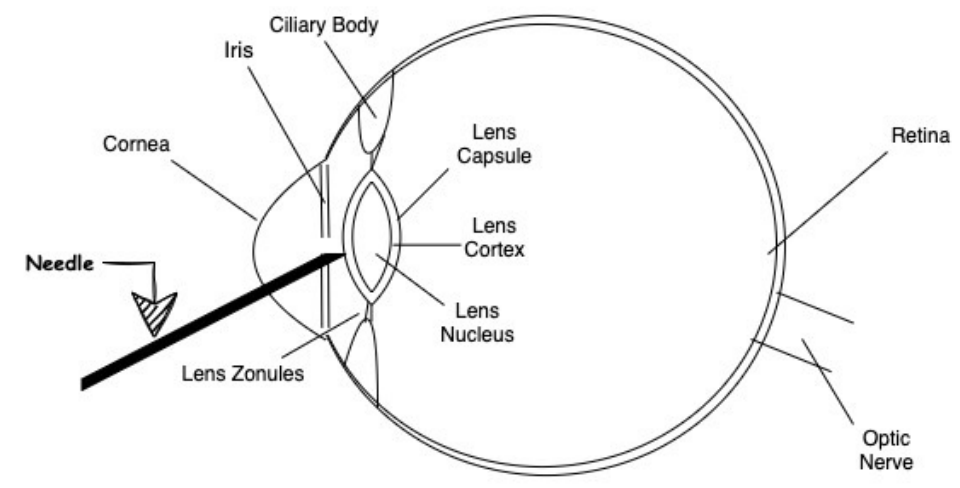

B.

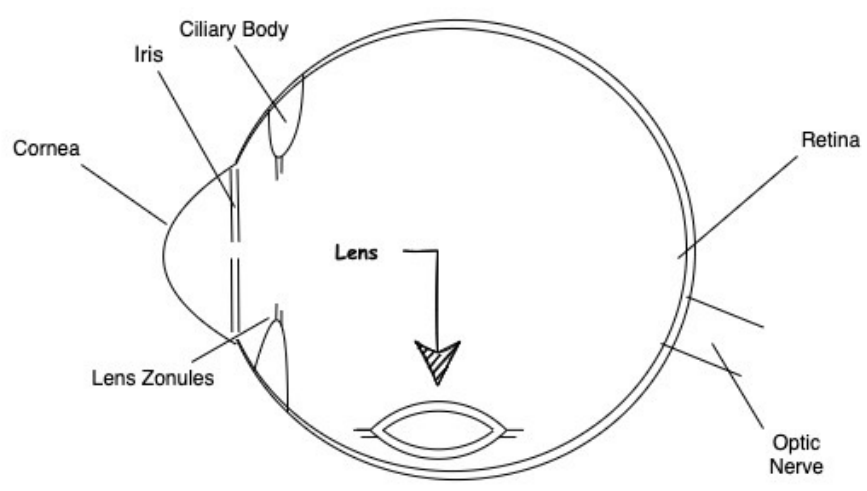

Figure 2. Diagram demonstrating couching techniques for cataract management, showing lens dislodgement with a needle (A) and post-operative lens position (B).

are used to remove the remaining cortex. Viscoelastic is again used to create space for the new synthetic lens. Finally, the synthetic, foldable lens is delivered and aqueous solution is used to induce corneal swelling and seal the incisions. Sutures are usually optional in this procedure but may be used depending on patient characteristics and surgeon preferences.

Alas, our story has reached its end. However, such a rapidly evolving technique will surely continue to undergo various changes and advancements. Let us now take a brief look at some recent advancements that may find their way into practice in the near or distant future.

\section{A Lens into the Future}

Cataract surgery continues to be an area of medicine that undergoes constant innovation, with regular emergence of new techniques that may be safer, faster, or more precise. One such example is the femtosecond laser, the use of which has increased in recent years. The femto laser is most commonly used for capsulorrhexis, as some surgeons report it offers more precision and better patient experience ${ }^{18}$. However, others report the technique as costly and unnecessary. Only time will tell whether this technique will become part of the standard of care for cataract management. Another technique increasing in popularity is intraoperative wavefront aberrometry, which allows surgeons to take refractive measurements (both pseudophakic and aphakic) during surgery ${ }^{19}$. These measurements aid in power selection and positioning of the IOL implant and may offer improved patient post-operative visual acuity. One limitation of this technique is the additional time during surgery to make these measurements, which may contribute to delayed uptake of this technique.

\section{Conclusion}

Cataract surgery may be one of medicine's greatest breakthroughs, offering a cure for an otherwise blinding condition. From couching to phacoemulsification, the journey through various techniques for cataract surgical management is unique, and exemplifies the innovation and ingenuity of physician-pioneers. There is no doubt that current procedures will continue to undergo improvements and adjustments as new technologies become readily available. As physicians and medical learners, perhaps all that is required is a keen eye. 


\section{Acknowledgements}

\section{Dr. Rishi Gupta for inspiring this work.}

\section{References}

1. Foster, A. Vision 2020: the cataract challenge. Community Eye Health. 2000;13(34):17-19.

2. Rachmiel R, Trope GE, Chipman ML, Buys YM. Cataract surgery rates in Ontario, Canada, from 1992 to 2004: more surgeries with fewer ophthalmologists. Can J Ophthalmol. 2007;42(4):539-542.

3. Haripriya A, Chang DF, Reena M, Shekhar M. Complication rates of phacoemulsification and manual small-incision cataract surgery at Aravind Eye Hospital. J Cataract Refract Surg. 2012;38(8):1360-1369. doi:10.1016/j.jcrs.2012.04.025

4. Schmitt C, Hockwin O. The mechanisms of cataract formation. J Inherit Metab Dis. 1990;13(4):501-508. doi:10.1007/ BF01799507

5. Kiziltoprak H, Tekin K, Inanc M, Goker YS. Cataract in diabetes mellitus. World J Diabetes. 2019;10(3):140-153. doi:10.4239/wjd.v10.i3.140

6. Bokhorst LP, Zegers RH. Staarsteek vroeger en nu [Couching then and now]. Ned Tijdschr Geneeskd. 2011;155:A3283.

7. Ademola-Popoola DS, Owoeye JF. Traditional couching for cataract treatment: a cause of visual impairment. West Afr I Med. 2004;23(3):208-210. doi:10.4314/wajm.v23i3.28122

8. Isawumi MA, Kolawole OU, Hassan MB. Couching techniques for cataract treatment in Osogbo, South west Nigeria. Ghana Med J. 2013;47(2):64-69.

9. Grzybowski A, Ascaso FJ. Sushruta in 600 B.C. introduced extraocular expulsion of lens material. Acta Ophthalmol. 2014;92(2):194-197. doi:10.1111/aos.12037
10. Obuchowska I, Mariak Z. Jacques Daviel--twórca zewnatrztorebkowej metody usuwania zaćmy [Jacques Daviel--the inventor of the extracapsular cataract extraction surgery]. Klin Oczna. 2005;107(7-9):567-571.

11. Rucker, CW. (1965). Cataract: a historical perspective. Invest Ophthalmol. 1965;4:377-383.

12. Daviel J. On a new method to cure cataract by extraction of the lens. Br J Ophthalmol. 1967;51(7):449-458. doi:10.1136/ bjo.51.7.449

13. Davis G. The Evolution of Cataract Surgery. Mo Med. 2016;113(1):58-62.

14. Trivedi RH, Apple DJ, Pandey SK, et al. Sir Nicholas Harold Ridley. He changed the world, so that we might better see it. Indian J Ophthalmol. 2003;51(3):211-216.

15. Moore DB, Harris A, Siesky B. The world through a lens: the vision of Sir Harold Ridley. Br J Ophthalmol. 2010;94(10):12771280. doi:10.1136/bjo.2009.163956

16. Visser N, Bauer NJ, Nuijts RM. Toric intraocular lenses: historical overview, patient selection, IOL calculation, surgical techniques, clinical outcomes, and complications. J Cataract Refract Surg. 2013;39(4):624-637. doi:10.1016/j.jcrs.2013.02.020

17. Kelman CD. Phaco-Emulsification and Aspiration: A New Technique of Cataract Removal: A Preliminary Report. Am J Ophthalmol. 2018;191:xxx-xl. doi:10.1016/j.ajo.2018.04.014

18. Aristeidou A, Taniguchi EV, Tsatsos M, et al. The evolution of corneal and refractive surgery with the femtosecond laser. Eye Vis (Lond). 2015;2:12. Published 2015 Jul 14. doi:10.1186/ s40662-015-0022-6

19. Hemmati HD, Gologorsky D, Pineda R 2nd. Intraoperative wavefront aberrometry in cataract surgery. Semin Ophthalmol. 2012;27(5-6):100-106. doi:10.3109/08820538.2012.708809 